\title{
The hydrophobicity of an amino acid residue in a flexible loop of KP-43 protease alters activity toward a macromolecule substrate
}

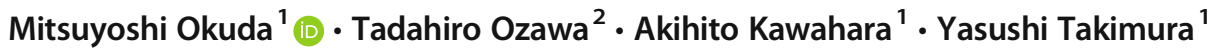

Received: 30 January 2020 /Revised: 2 August 2020 / Accepted: 11 August 2020 / Published online: 25 August 2020

(C) The Author(s) 2020

\begin{abstract}
$\mathrm{KP}-43$, a 43-kDa alkaline serine protease, is resistant to chemical oxidants and surfactants, making it suitable for use in laundry detergents. An amino acid residue at position 195, in a unique flexible loop that binds a $\mathrm{Ca}^{2+}$ ion, dramatically affects the proteolytic activity and thermal stability of KP-43. In the present study, we obtained 20 variants with substitutions at position 195 and investigated how these residues affect hydrolytic activity toward a macromolecular substrate (casein) and a synthetic tetrapeptide (AAPL). At pH 10, the variant with the highest caseinolytic activity, Tyr195Gln, exhibited 4.4-fold higher activity than the variant with the lowest caseinolytic activity, Tyr195Trp. A significant negative correlation was observed between the hydrophobicity of the residue at position 195 and caseinolytic activity at $\mathrm{pH} \mathrm{8-10.} \mathrm{At} \mathrm{pH} 7$, the correlation became weak; at $\mathrm{pH} 6$, the correlation reversed to positive. Unlike casein, in the case of hydrolysis of AAPL, no correlation was observed at $\mathrm{pH} 10$ or $\mathrm{pH}$ 6. Because the amino acid residue at position 195 is located on the protein surface and considered sufficiently far from the active cleft, the variation in caseinolytic activity between the 20 variants was attributed to changes in interaction efficiency with different states of casein at different $\mathrm{pH}$ values. To improve the enzymatic activity, we propose substituting amino acid residues on the protein surface to change the efficiency of interaction with the macromolecular substrates.
\end{abstract}

\section{Key points}

- A single amino acid residue on the protein surface markedly changed enzyme activity.

- The hydrophobicity of the amino acid residue and enzyme activity had a correlation.

- The key amino acid residue for substrate recognition exists on the protein surface.

Keywords Subtilisin $\cdot$ Protein surface $\cdot$ Caseinolytic activity $\cdot$ Macromolecular substrate $\cdot$ Protein engineering $\cdot$ Surface engineering

\section{Introduction}

Proteases are enzymes widely used in a variety of industrial applications, such as detergents, food and feed production,

Electronic supplementary material The online version of this article (https://doi.org/10.1007/s00253-020-10826-2) contains supplementary material, which is available to authorized users.

Mitsuyoshi Okuda

okuda.mitsuyoshi@kao.com

1 Biological Science Research, Kao Corporation, 1334 Minato, Wakayama, Wakayama 640-8580, Japan

2 Biological Science Research, Kao Corporation, 2606 Akabane, Ichikai, Haga, Tochigi 321-3497, Japan peptide synthesis, leather processing, silver recovery, and waste management (Kalisz 1988). Bacterial alkaline serine proteases (e.g., subtilisins) are particularly favored because of their high productivity, high stability, and relatively low substrate specificity (Gupta et al. 2002). Due to their industrial importance, subtilisins are one of the most-studied model enzymes for protein engineering, and many excellent studies have been carried out to increase the catalytic activity, change the substrate specificity, and improve the stability of subtilisins under various conditions (Bryan 2000; Wells and Estell 1988).

Analyses of three-dimensional structures of subtilisins and subtilisin/inhibitor complexes revealed the residues involved in substrate binding in the active cleft (Bode et al. 1986; Hirono et al. 1984; Mcphalen et al. 1985). These residues were the first targets for protein engineering, particularly for improving the catalytic activity of the 
enzymes. For example, Glu156, Gly169, and Tyr217 of subtilisin BPN' were substituted with Ser, Ala, and Leu, respectively (corresponding to subtilisin Carlsberg, which exhibits greater catalytic efficiency for synthetic peptides with neutral and hydrophobic P1 residues). The subtilisin BPN' triple mutant exhibited increased catalytic efficiency for several P1 substrates, 3- to 31-fold higher than that of the wild-type enzyme. Furthermore, the P1 substrate preference of the triple mutant changed to that of subtilisin Carlsberg (Wells et al. 1987a, 1987b). However, these mutations in the catalytic cleft tend to result in biased substrate preference. In general, a mutant that prefers acidic $\mathrm{P} 1$ residues does not prefer basic $\mathrm{P} 1$ residues, and a mutant that prefers bulky P1 residues does not prefer small P1 residues (Estell et al. 1986; Wells et al. 1987a, 1987b).

In addition to residues in the active cleft, charged residues on the protein surface far from the active center reportedly affect catalytic activity (de Kreij et al. 2002; Thomas et al. 1985). Mutations of charged residues located $\geq 10 \AA$ from the active center alter the catalytic efficiency toward synthetic peptides and the activity $\mathrm{pH}$ dependence. These effects are attributed to long-distance electrostatic interactions with residues in the active center and changes in the $\mathrm{pKa}$ of residues in the active center. However, improvements in catalytic efficiency toward synthetic peptides do not necessarily reflect enhanced activity for proteinaceous substrates, which have 20 different residues subject to cleavage (Taguchi et al. 2000).

$\mathrm{KP}-43$, an alkaline serine protease secreted by Bacillus sp. KSM-KP43 (FERM BP-6532), is a member of a new subfamily of subtilisins characterized as "oxidatively stable alkaline proteases." KP-43 has a molecular mass of approximately $43 \mathrm{kDa}$ and is resistant to chemical oxidants and surfactants (Saeki et al. 2000; Saeki et al. 2002). Due to these properties, KP-43 has been incorporated into commercial laundry detergents.

In a previous study, we obtained a mutant exhibiting simultaneous increases in proteolytic activity, thermal stability, and surfactant stability via random mutagenesis (Okuda et al. 2013). We revealed that a single amino acid substitution (Tyr to Cys) at position 195 in a unique flexible loop that binds a $\mathrm{Ca}^{2+}$ ion markedly affects the enzyme's function. Although the Tyr195Cys mutant exhibited enhanced proteolytic activity toward casein (a macromolecule substrate), it did not exhibit enhanced catalytic efficiency toward synthetic peptides.

In the present study, we obtained 20 variants with substitutions at position 195 and investigated how these residues affect the hydrolytic activity of KP-43 toward both casein and a synthetic peptide. We also discuss the importance of the relationship between the properties of the amino acid residues on the protein surface and the state of the macromolecule substrates.

\section{Materials and methods}

\section{Bacterial strains and plasmids}

The gene encoding KP-43 (GenBank ID: AB051423) was subcloned into the expression plasmid pHSP64, which consists of pHY300PLK (Takara) harboring the promoter region of the Bacillus sp. KSM-64 gene encoding alkaline endoglucanase, generating the plasmid pHSP-KP43 (Okuda et al. 2013). pHSP-KP43 was expressed in a protease-deficient derivative of Bacillus sp. KSM-9865 (FERM BP-10139).

\section{Site-directed mutagenesis}

Site-directed mutagenesis at the amino acid residue at position 195 of KP-43 was performed using the overlapping PCR method (Ho et al. 1989). Mutagenesis PCR was carried out with pHSP-KP43 as the template using the primers is listed in Table S1 (ESM1). Two external primers, a sense primer (KP43-BamHI-F; 5 '-end of the open reading frame [ORF] of KP43 with a BamHI site) and an antisense primer (KP-43-XbaIR; 3'-end of the ORF of KP-43 with an $X b a$ I site), were also used to amplify KP-43 mutant genes using the overlapping PCR method. Amplified DNA fragments were digested with BamHI and $X b a \mathrm{I}$ and ligated into pHSP64.

\section{Protein expression and purification}

The recombinant plasmid harboring the ORF encoding the KP-43 mutant gene was transformed into the proteasedeficient derivative of Bacillus sp. KSM-9865 by electroporation (model Gene Pulser II; Bio-Rad) followed by selection on Luria-Bertani (LB) agar containing $1 \%(\mathrm{w} / \mathrm{v})$ skim milk (Difco), $0.05 \%$ (w/v) $\mathrm{Na}_{2} \mathrm{CO}_{3}$, and $15 \mu \mathrm{g} / \mathrm{mL}$ tetracycline (Sigma). Tetracycline-resistant cells were selected as transformants and grown aerobically at $30{ }^{\circ} \mathrm{C}$ for $72 \mathrm{~h}$ in liquid medium composed of $8.0 \%(\mathrm{w} / \mathrm{v})$ Polypepton $\mathrm{S}$ (Nippon Pharmaceutical), 0.5\% (w/v) fish meal extract (Wako Pure Chemicals), 0.1\% (w/v) yeast extract (Difco), $0.1 \%$ (w/v) $\mathrm{KH}_{2} \mathrm{PO}_{4}, 0.02 \%$ (w/v) $\mathrm{MgSO}_{4} \cdot 7 \mathrm{H}_{2} \mathrm{O}, 10.0 \%$ (w/v) maltose (autoclaved separately), and $20 \mu \mathrm{g} / \mathrm{mL}$ tetracycline.

\section{Purification of recombinant proteases}

KP-43 wild-type and mutant enzymes were purified as follows. The fermentate was cleared by centrifugation, and 50 $\mathrm{mL}$ of the supernatant was dialyzed overnight in $10 \mathrm{mM}$ Tris$\mathrm{HCl}$ buffer ( $\mathrm{pH} 7.5$ ) containing $2 \mathrm{mM} \mathrm{CaCl}_{2}$. The retentate was applied to a DEAE-Toyopearl 650C column (Tosoh) equilibrated with the same buffer. The column was washed with the same buffer, and non-absorbed active fractions were 
collected and concentrated by ultrafiltration. Protein levels were determined with a DC-protein assay kit (Bio-Rad) using bovine serum albumin as the standard.

\section{SDS-PAGE analysis}

The purity of each purified protease was assessed by SDSPAGE analysis according to the method of Laemmli (1970). A total of $150 \mathrm{ng}$ of each purified enzyme was loaded onto an Any KD Mini-Protean TGX Stain-Free Gel (Bio-Rad). Chemifluorescence signals were captured using a Chemi Doc MP Imaging system (Bio-Rad). Precision Plus Protein Unstained Standards (Bio-Rad) were used as molecular weight markers.

\section{Enzyme assay}

The effect of $\mathrm{pH}$ on caseinolytic activity was determined as follows. Casein (Hammerstein casein [Merck]) solution $(0.3 \%)$ was prepared in $50 \mathrm{mM}$ Britton-Robinson buffer (50 $\mathrm{mM}$ phosphoric acid/acetic acid/boric acid; with $\mathrm{pH}$ adjusted with $\mathrm{NaOH}$ ) at $\mathrm{pH}$ values ranging from 6 to 10 , and 200 $\mu \mathrm{L}$ of $0.3 \%$ casein solution was dispensed into the wells of a 96-well Flat-Bottom Assay Plate (Iwaki). After preincubation at $30{ }^{\circ} \mathrm{C}$ for $10 \mathrm{~min}$ in a Bio Shaker M/BR-024 (Taitec), a suitably diluted solution of enzyme sample $(20 \mu \mathrm{L})$ was added and mixed gently by shaking in the Bio Shaker M/BR-024 at $30^{\circ} \mathrm{C}$ for $15 \mathrm{~min}$. The reaction was stopped by addition of 100 $\mu \mathrm{L}$ of $5 \%$ trichloroacetic acid. Next, $300 \mu \mathrm{L}$ of the mixture was transferred into a Filter plate MultiScreen-HV (Merck Millipore) and centrifuged at $2500 \mathrm{rpm}$ using a himac CF7D2 (Hitachi) to remove denatured protein. Subsequently, $200 \mu \mathrm{L}$ of the filtrate was transferred into the wells of a UV Flat-Bottom Microtiter Plate (Thermo Fisher Scientific). The peptide concentration of the filtrate was determined by monitoring at $280 \mathrm{~nm}$ using an Infinite M200 microplate reader (Tecan). One unit (U) of caseinolytic activity was defined as the amount of enzyme needed to produce acidsoluble peptide equivalent to $1 \mu \mathrm{mol}$ of L-Tyr per min.

\section{Determination of kinetic parameters}

The synthetic peptide, N-glutaryl-L-Ala-L-Ala-L-Pro-L-Leu$p$-nitroanilide (AAPL), was obtained from the Peptide Institute. Kinetic parameters were measured using six different concentrations of AAPL $(0.3-10 \mathrm{mM})$ at $30^{\circ} \mathrm{C}$ for $10 \mathrm{~min}$ in $50 \mathrm{mM}$ borate buffer ( $\mathrm{pH} 10)$ and $50 \mathrm{mM}$ phosphate buffer (pH 6). The initial rate of AAPL hydrolysis was determined as described above. Michaelis-Menten kinetic parameters $(\mathrm{Km}$ and $k$ cat) were determined from Lineweaver-Burk plots $(1 /[\mathrm{S}]$ versus $1 / \mathrm{v}$ : [S], concentration of the substrate; $\mathrm{v}$, velocity of the reaction) by least-squares linear regression using Microsoft Excel software.

\section{Tryptophan fluorescence measurements}

Enzyme samples were set up in a 96-well Flat-Bottom Assay Plate (Iwaki) in a total volume of $200 \mu \mathrm{L}$ per well. Fluorescence was measured at room temperature in $200 \mu \mathrm{L}$ of $50 \mathrm{mM}$ Britton-Robinson buffer (pH 6 and $\mathrm{pH} 10$ ) containing $30 \mu \mathrm{M}$ enzyme using an Infinite M200 PRO microplate reader (Tecan). Tryptophan fluorescence was excited at $285 \mathrm{~nm}$ (bandwidth $5 \mathrm{~nm}$ ), and the emission was scanned from 285 to $450 \mathrm{~nm}$ (bandwidth $20 \mathrm{~nm}$ ). All spectra were corrected for background fluorescence by subtracting a blank scan of the buffer.

\section{Circular dichroism measurements}

Circular dichroism (CD) measurements were performed at room temperature using a CD spectrometer J720 (Jasco) in $10 \mathrm{mM}$ Britton-Robinson buffer (pH 6 and $\mathrm{pH} 10)$ containing $0.1 \mathrm{mg} / \mathrm{mL}$ of enzyme. For CD measurements, a $0.1-\mathrm{cm}$ lightpath cuvette was used. The CD spectra were recorded over the range 190 to $260 \mathrm{~nm}$ with an interval of $1 \mathrm{~nm}$ and four accumulations of data. All spectra were corrected for background by subtracting a blank scan of the buffer. Spectral data are expressed as molar ellipticity, $[\theta]\left(\mathrm{deg} \mathrm{cm}^{2} \cdot \mathrm{dmol}^{-1}\right)$, based on mean amino acid residue weight (MRW) assuming an average weight for KP-43 of 104. The molar ellipticity was determined as $[\theta] \lambda=(\theta \times 100 \mathrm{MRW}) /(\mathrm{cl})$, where $\mathrm{c}$ represents the protein concentration in $\mathrm{mg} / \mathrm{mL}$, 1 represents the light path length in $\mathrm{cm}$, and $\theta$ represents the measured ellipticity in degrees at wavelength $\lambda$.

\section{Molecular simulation}

All data sets were processed on a Windows 7 personal computer using the Discovery Studio software package (Biovia). Figures were prepared using a DS Visualizer (Biovia). The Streptomyces subtilisin inhibitor (SSI) and KP-43 combined structure were constructed according to the superimposed method using the X-ray crystallographic structure of KP-43 (PDB ID: 1WMD) and the structure of subtilisin BPN' combined with SSI (PDB ID: 2SIC).

\section{Results}

\section{Three-dimensional structure of KP-43}

Figure 1a shows the three-dimensional structure of KP-43 (PDB ID: 1WMD). The crystal structure indicates that KP43 consists of two domains, a subtilisin-like $\alpha / \beta$ domain $(\mathrm{N}$ domain) and a C-terminal jelly roll $\beta$-barrel domain (C-domain). Although the primary structure of KP-43 apparently differs from that of other subtilisins, the tertiary structure of 
Fig. 1 Three-dimensional structure of KP-43. a Threedimensional structure of KP-43. b Three-dimensional structure of shown as a ribbon representation. Calcium ion is shown as a green ball. Asp30, His68, and Ser255, comprising the catalytic triad of $\mathrm{KP}-43$, are shown as CPK representations (in yellow). Tyr195 is shown as a CPK representation (in red). Phe192, Phe205, Phe226, and Trp241 are shown as CPK representations (in blue). The structures were created using DS Visualizer (Biovia) the N-domain of KP-43. KP-43 is

(a)

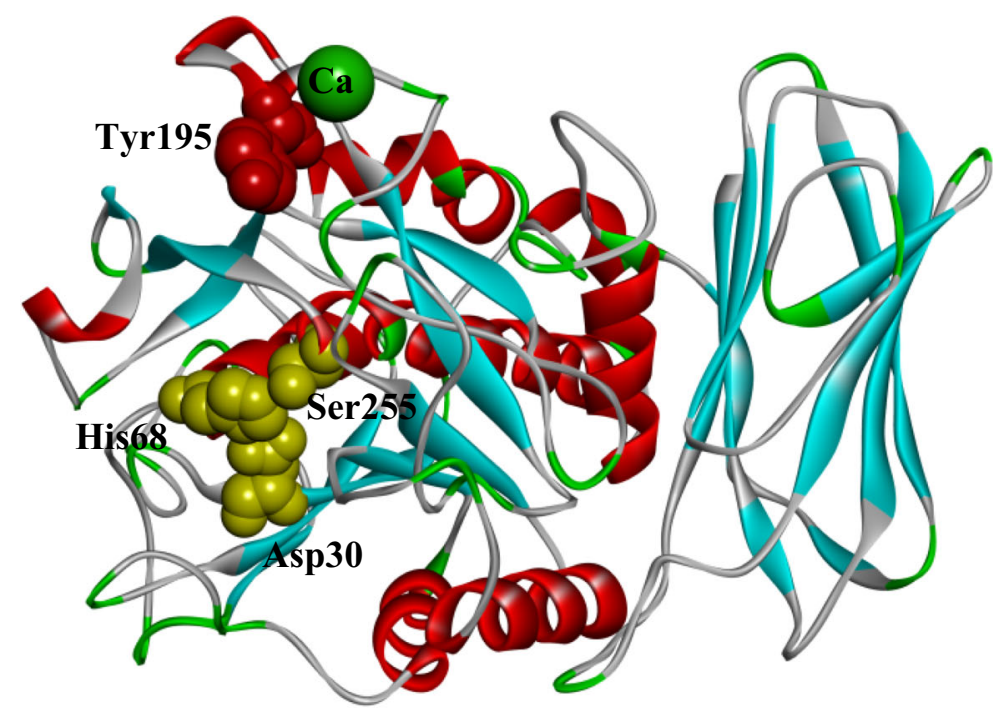

N-domain

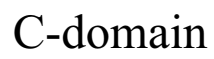

(b)

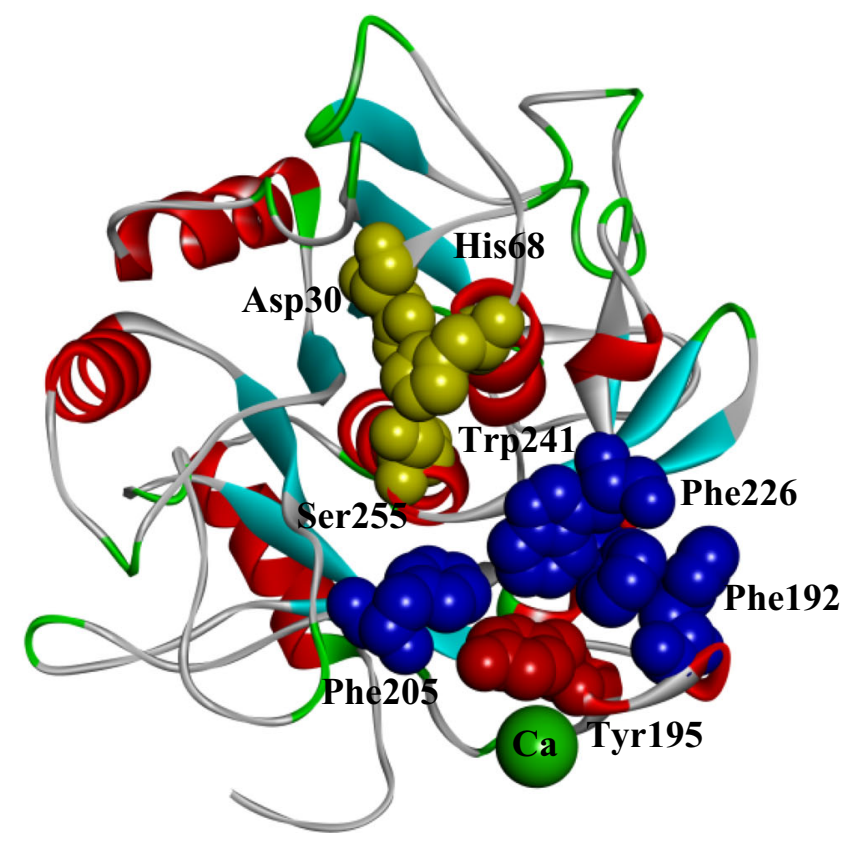

the N-domain of KP-43 is highly similar to that of other subtilisins (Nonaka et al. 2004).

Tyr195 is located within a $\mathrm{Ca}^{2+}$-binding loop distant from the active center. The distance between Tyr195 and each residue of the catalytic triad (Asp30, His68, and Ser255) was 20 $\AA, 16 \AA$, and $15 \AA$, respectively. Nevertheless, the amino acid residue at position 195 affected multiple properties of the enzyme, and multiple alignment analyses indicated no amino acid residue corresponding to position 195 in other subtilisin homologs (Saeki et al. 2000).

Figure $1 \mathrm{~b}$ shows four hydrophobic aromatic amino acid residues surrounding Tyr195: Phe192, Phe205, Phe226, and
Trp241 (blue CPK representation). The distance between Tyr195 and Phe192, Phe205, Phe226, and Trp241 was 6.7 $\AA, 4.0 \AA, 4.0 \AA$, and $4.4 \AA$, respectively.

\section{Caseinolytic activity of mutant enzymes at various pHs}

Twenty KP-43 variants with a different amino acid substitution at position 195 were obtained and purified by column chromatography. The 20 purified variants gave a single band on SDS-PAGE analysis (Fig. S1, ESM1). All 20 variants exhibited almost the same productivity, as the coefficient of 
variation for the supernatant protein concentration was less than $10 \%$ for each variant (data not shown). This result indicates that the type of amino acid residue at position 195 has no effect on protein folding or protein secretion.

We measured the specific activity of each variant toward casein at $\mathrm{pH}$ 6, 7, 8, 9, and 10 (Table S2, ESM1). At pH 10 (the optimum $\mathrm{pH}$ for KP-43), the Y195W (Tyr195Trp) variant exhibited the lowest specific activity, whereas the Y195Q (Tyr195Gln) variant exhibited the highest specific activity, which was 4.4-fold higher than that of the Y195W variant. At pH 6, the Y195R (Tyr195Arg) variant exhibited the lowest specific activity, whereas the Y195I (Tyr195Ile) variant exhibited the highest specific activity, which was 1.8-fold higher than that of the Y195R variant.

Figure 2 shows the profile of caseinolytic activity for each variant at $\mathrm{pH}$ ranging from 6 to 10. As shown in Figure 2a-c, three types of $\mathrm{pH}$ profile were observed. Figure $2 \mathrm{a}$ shows that 8 variants exhibited relatively high specific activity at $\mathrm{pH} 10$.

Although KP-43 is an alkaline protease, wild-type KP-43 exhibited relatively high specific activity at $\mathrm{pH}$ 7, $90 \%$ of the activity at pH 10 (Fig. 2c). By contrast, in the case of $\mathrm{M}$ protease, a high-alkaline protease, the specific activity at $\mathrm{pH} 7$ is only $67 \%$ of that at $\mathrm{pH} 10$ (Kobayashi et al. 1995; Siezen and Leunissen 1997). Thus, high specific activity at neutral $\mathrm{pH}$ is a characteristic specific to KP-43.
The caseinolytic activity $\mathrm{pH}$ profile of each variant changed dramatically depending on the type of substitution. As shown in Fig. 2a, eight KP-43 variants (Gln, Thr, Glu, Arg, Lys, Gly, Asp, and Asn substitution at position 195) exhibited a $\mathrm{pH}$ profile similar to that of a high-alkaline protease. As shown in Fig. 2c, the KP-43 variant with a Phe substitution exhibited the same $\mathrm{pH}$ profile as that of wild-type (Tyr) KP43. The variant substituted with Trp, another aromatic amino acid residue, exhibited specific activity lower than that of wild-type KP-43. Although KP-43 variants with hydrophobic aromatic amino acid residues at position 195 exhibited relatively low activity, their activity was generally constant, independent of $\mathrm{pH}$.

The caseinolytic activity $\mathrm{pH}$ profiles of variants with other amino acid residue substitutions (Ser, Ala, Val, Leu, Cys, Met, Pro, His, and Ile) were between those of high-alkaline-type proteases and wild-type KP-43 (Fig. 2b).

\section{Effect of the hydrophobicity of the amino acid residue at position 195 on caseinolytic activity}

The substitution at position 195 of KP-43 had a dramatic effect on caseinolytic activity. Figure 3 shows how the hydrophobicity of the amino acid residue at position 195 affected the caseinolytic activity at various pHs. Hydrophobicity of the amino acid residues was expressed using the hydrophobicity (a)

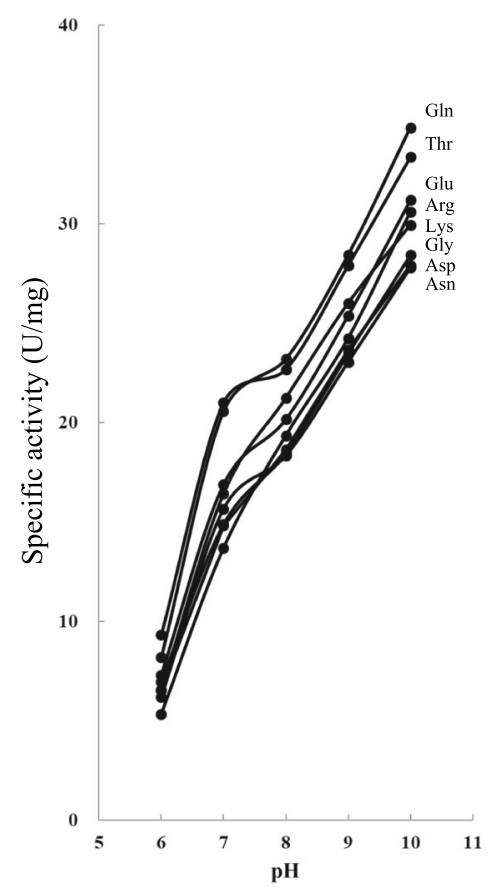

(b)

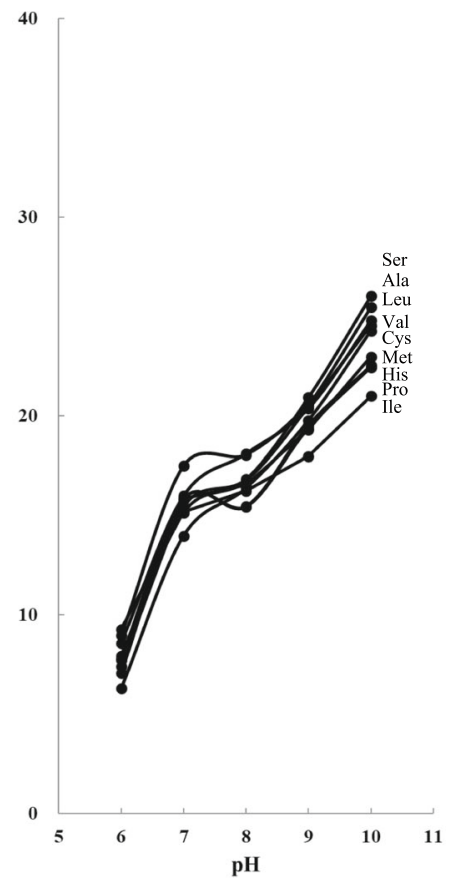

(c)

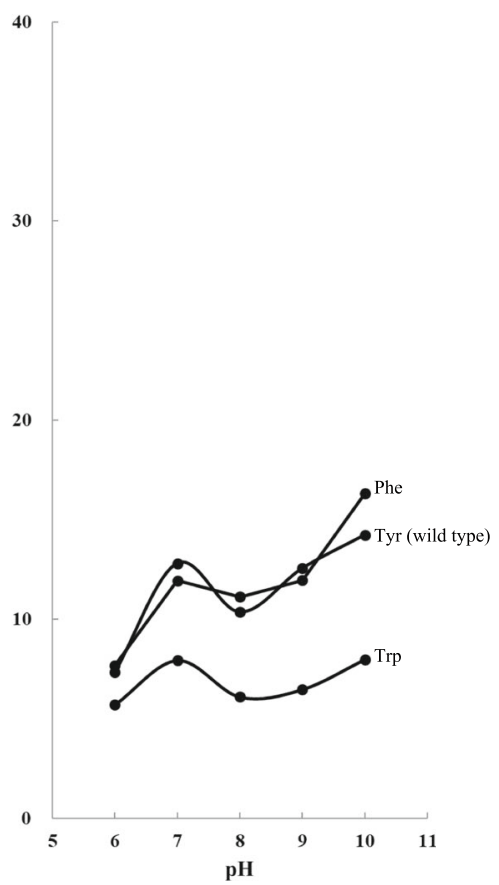

Fig. 2 Effect of $\mathrm{pH}$ on the caseinolytic activity of $20 \mathrm{KP}-43$ variants. a Effect of $\mathrm{pH}$ on the caseinolytic activity of 8 high-activity KP-43 variants. b Effect of $\mathrm{pH}$ on the caseinolytic activity of 9 mid-activity KP-43 variants. $\mathbf{c}$ Effect of $\mathrm{pH}$ on the caseinolytic activity of 3 low-activity KP-43 variants. Enzymes were assayed at $30^{\circ} \mathrm{C}$ for $15 \mathrm{~min}$ at the indicated $\mathrm{pH}$ in $50 \mathrm{mM}$ Britton-Robinson buffer. Data points are plotted as the mean of two independent experiments run in duplicate 
Fig. 3 Relationship between hydrophobicity and caseinolytic activity of $20 \mathrm{KP}-43$ variants. a, $\mathbf{b}, \mathbf{c}, \mathbf{d}$, and e show the relationship at $\mathrm{pH} 10,9,8,7$, and 6 , respectively. The amino acid hydrophobicity scale was described by Black and Mould (1991). Line represents the leastsquares linear regression with the correlation coefficient $(r)$. Data points are plotted as the mean of two independent experiments run in duplicate (a)

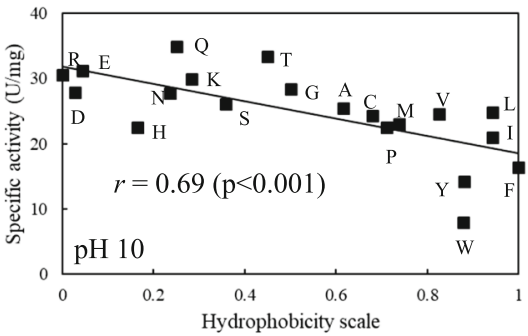

(b)

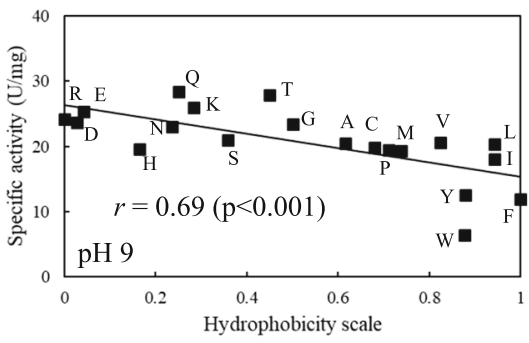

(c)

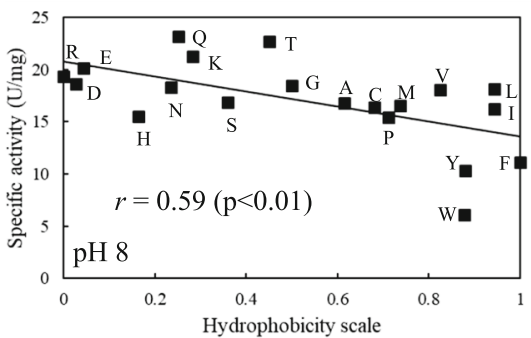

(d)

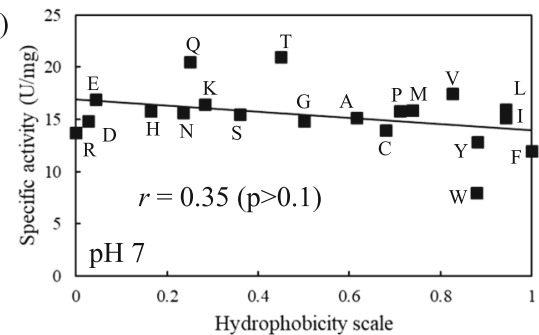

(e)

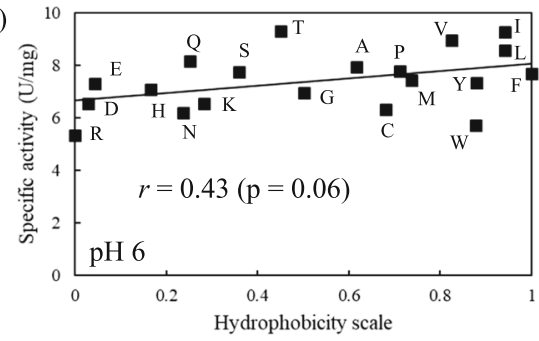

scale values of Black and Mould (1991). Figure 3a shows the correlation between the hydrophobicity of the amino acid residue at position 195 and the caseinolytic activity at $\mathrm{pH} 10$. As mentioned above, at $\mathrm{pH}$ 10, variants with charged amino acid residues (e.g., Glu, Asp, Arg, or Lys) or hydrophilic residues (e.g., Gln, Asn, or Thr) tended to exhibit high specific activity. Conversely, variants with hydrophobic amino acid residues (e.g., Leu, Ile, Tyr, Trp, or Phe) tended to exhibit low specific activity. As shown in Fig. 3a, the correlation was negative (correlation coefficient $=0.69 ; p<0.001)$.

Because KP-43 is an alkaline serine protease, the specific activity decreases with decreasing $\mathrm{pH}$. In the range of $\mathrm{pH} 10$ to $\mathrm{pH} 8$, the rate of decline in the specific activity of each variant was approximately $0.8-0.9(\mathrm{pH} \mathrm{9/pH} 10$ and $\mathrm{pH} \mathrm{8/pH} \mathrm{9).}$ Thus, the positional relationship of each variant was unchanged in Fig. 3a, b, and c. The correlation coefficient was $0.69(p<0.001)$ at $\mathrm{pH} 9$ (Fig. 3b) and $0.59(p<0.01)$ at $\mathrm{pH} 8$ (Fig. 3c).

At $\mathrm{pH} 7$, the rate of decline in specific activity $(\mathrm{pH} 7 / \mathrm{pH} 8)$ changed dramatically compared with either $\mathrm{pH} 9 / \mathrm{pH} 10$ or $\mathrm{pH}$ $8 / \mathrm{pH} 9$. In particular, variants with a Trp, Tyr, Phe, Pro, or His residue exhibited a rate of decline $>1.0$, meaning that these variants are more active at $\mathrm{pH} 7$ than $\mathrm{pH} 8$. Consequently, the correlation between hydrophobicity and specific activity became weaker, as the correlation coefficient was only 0.35 ( $p=$ 0.12) at pH 7 (Fig. 3d).
As shown in Fig. 3e, at $\mathrm{pH}$ 6, although the variation in specific activity for all variants was at its minimum and the correlation between hydrophobicity and specific activity was weak, the correlation became positive, with a correlation coefficient of $0.43(p=0.06)$. Therefore, these results indicate that the amino acid residue at position 195 of KP-43 can have an opposite effect on proteolysis depending on $\mathrm{pH}$.

\section{Effect of amino acid residue hydrophobicity on the hydrolysis of a synthetic peptide}

To investigate the mechanism underlying the differences in proteolytic activity of the variants, we assayed the hydrolytic activity of each variant toward a synthetic peptide, AAPL, instead of the normal casein substrate. The kinetic parameters for hydrolysis of AAPL at pH 10 and $\mathrm{pH} 6$ are shown in Table S3 (ESM1).

At $\mathrm{pH} \mathrm{10,} \mathrm{the} \mathrm{Y195G} \mathrm{(Tyr195Gly)} \mathrm{variant} \mathrm{exhibited} \mathrm{the}$ lowest $k$ cat $/ K m$ value, whereas the Y195R (Tyr195Arg) variant exhibited the highest $k \mathrm{cat} / \mathrm{Km}$ value, which was 2.5 -fold higher than that of the Y195G variant. Similarly, at pH 6, the Y195G exhibited the lowest $k \mathrm{cat} / \mathrm{Km}$ value and the Y195R variant the highest, which was 3.1-fold higher than that of the Y195G variant. With respect to casein proteolysis, the rank of variants by $k$ cat $/ K m$ value was the same between $\mathrm{pH} 10$ and $\mathrm{pH} 6$. 
Figure 4 shows how the hydrophobicity of the amino acid residue at position 195 affected the $k$ cat $/ K \mathrm{~m}$ value at $\mathrm{pH} 10$ and $\mathrm{pH}$ 6. Unlike the casein substrate, no correlation between hydrophobicity and $k \mathrm{cat} / \mathrm{Km}$ was observed at either $\mathrm{pH} 10$ or pH 6. Furthermore, the positional relationship of each variant was unchanged between $\mathrm{pH} 10$ and $\mathrm{pH} 6$ (Fig. 4a and b). Consequently, the amino acid substitution at position 195 had a completely different effect on AAPL and casein hydrolysis.

\section{Effect of the amino acid substitution at position 195 on the conformation of KP-43}

To examine the effect of the amino acid substitution at position 195 on the conformation of KP-43, tryptophan fluorescence and CD measurements were carried out. As shown in Fig. 2, the 20 variants were classified into three types depending on caseinolytic activity $\mathrm{pH}$ profile. Y195Q and Y195S were chosen as typical variants exhibiting the highest caseinolytic specific activity at pH 10 (as shown in Fig. 2a and b, respectively).

(a)

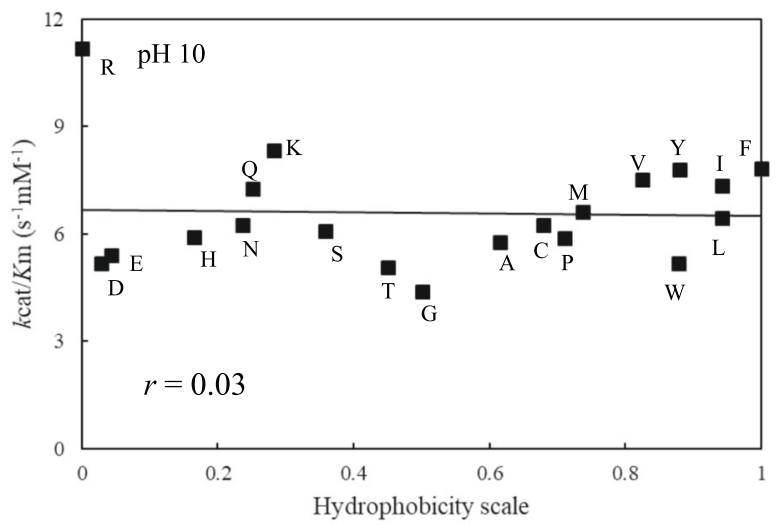

(b)

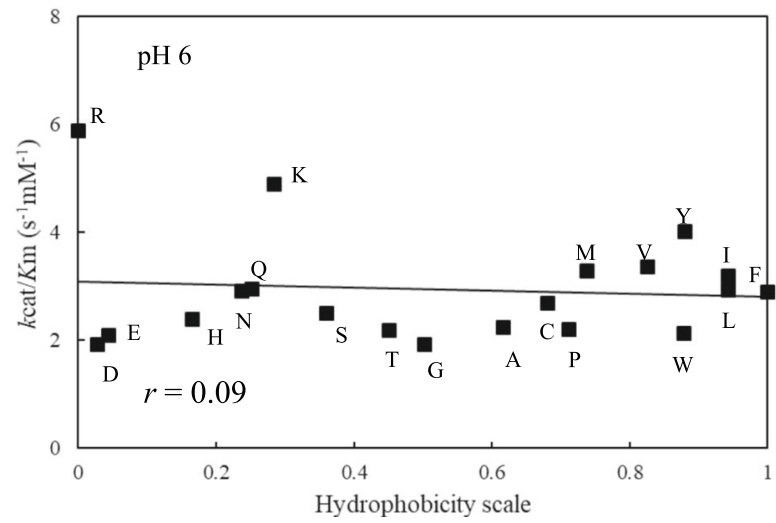

Fig. 4 Relationship between hydrophobicity and catalytic efficiency toward AAPL of $20 \mathrm{KP}-43$ variants. $\mathbf{a}$ and $\mathbf{b}$ show the relationship at $\mathrm{pH} 10$ and $\mathrm{pH}$ 6, respectively. The amino acid hydrophobicity scale is from the scale set described by Black and Mould (1991). Line represents the least-squares linear regression with the correlation coefficient $(r)$. Data points are plotted as the mean of two independent experiments run in duplicate
Figure 5a and b show a comparison of tryptophan fluorescence spectra of Y195Q, Y195S, and wild-type KP-43 at pH 10 and $\mathrm{pH}$ 6, respectively. Y195Q, Y195S, and wild-type KP43 exhibited maximum fluorescence intensity at $334 \mathrm{~nm}$, and no peak shift was observed among the three enzymes at either $\mathrm{pH} 10$ or $\mathrm{pH} 6$.

Figure 5c and d show CD spectra of the three enzymes at $\mathrm{pH} 10$ and $\mathrm{pH}$, respectively. The spectra of Y195Q, Y195S, and wild-type KP-43 were almost the same, with a maximum at $194 \mathrm{~nm}$ and minimum at 218-219 nm, as derived from the $\alpha$-helix, at both $\mathrm{pH}$ 10 and $\mathrm{pH}$ 6. These results indicate that the amino acid substitutions at position 195 had no effect on the secondary and tertiary structure of KP-43 at either $\mathrm{pH} 10$ or $\mathrm{pH} 6$.

\section{Molecular simulation of KP-43 and SSI docking}

Figure 6 shows a docking model of the KP-43 and SSI (PDB ID; 2SIC) complex. SSI is a very strong inhibitor of serine proteases, including KP-43 (data not shown). Previous studies indicated that Met73 of SSI is a $\mathrm{P} 1$ residue accommodated in the S1 site of subtilisin BPN'. Ser255 of KP-43 acts as a nucleophile that attacks the peptide bond between Met73 and Val74 ( $\mathrm{P} 1$ ' residue) of SSI (Fig. 6). The docking model suggested that Tyr195 interacts with Tyr75 of SSI (P2' residue). The distance between Tyr195 and Tyr75 of SSI was $3.1 \AA$.

\section{Discussion}

A previous study revealed that substitution of Tyr with Cys at position 195, located in the surface loop of KP-43, simultaneously increases the enzyme's proteolytic activity and thermal/surfactant stability (Okuda et al. 2013). Many protein engineering studies have sought to improve the catalytic activity of subtilisin, revealing that amino acid residues on the protein surface, far from the active cleft, markedly affect the proteolytic activity toward macromolecular substrates (e.g., skim milk or casein).

Feller et al. (2010) investigated the relationship between protein surface electrostatic potential and specific activity toward immobilized bovine serum albumin. The authors compared the parent enzyme with chymotrypsin-like serine protease from Cellulomonas bogoriensis with a net charge ranging from -2 to +4 . Positively charged mutants exhibited increased reaction rates at high ionic strength and decreased reaction rates at low ionic strength (Feller et al. 2010).

Jakob et al. (2013) substituted Asn and Gln residues on the surface of Bacillus gibsonii alkaline protease with Asp and Glu, respectively. The Asn253Asp and Gln256Glu double mutant exhibited increased proteolytic activity, a shift in 
Fig. 5 Comparison of tryptophan fluorescence spectra and CD spectra of Y195Q, Y195S, and wild-type KP-43. a and b show tryptophan fluorescence spectra at pH 10 and p $\mathrm{H} 6$, respectively. c and $\mathbf{d}$ show CD spectra at $\mathrm{pH} 10$ and $\mathrm{pH} 6$, respectively. Red, orange, and black lines represent Y195Q, Y195S, and wild-type KP-43, respectively (a)

(b)

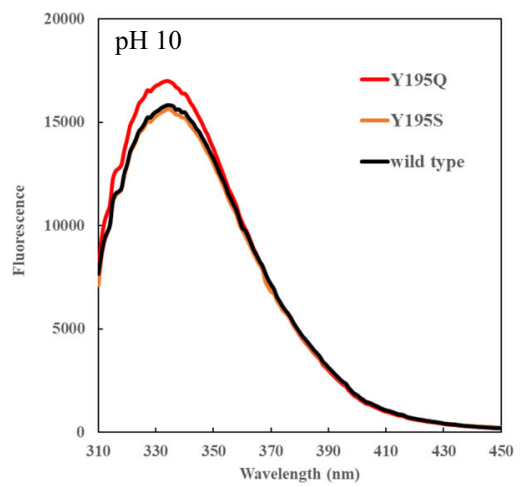

(c)

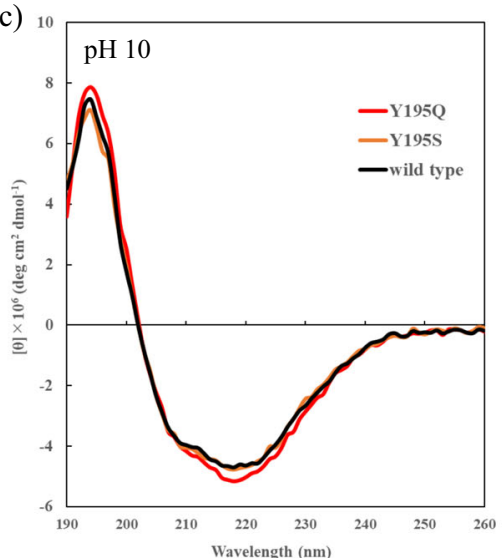

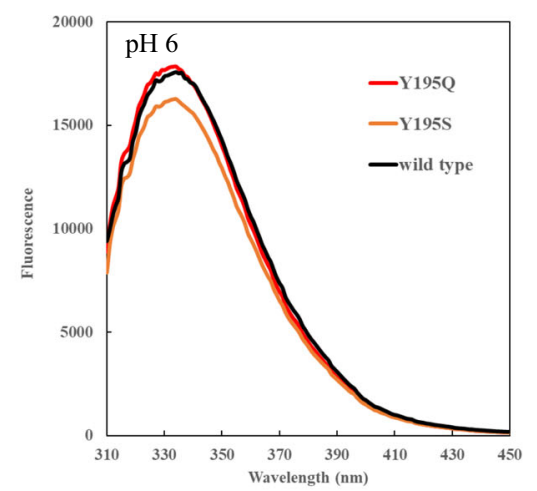

(d)

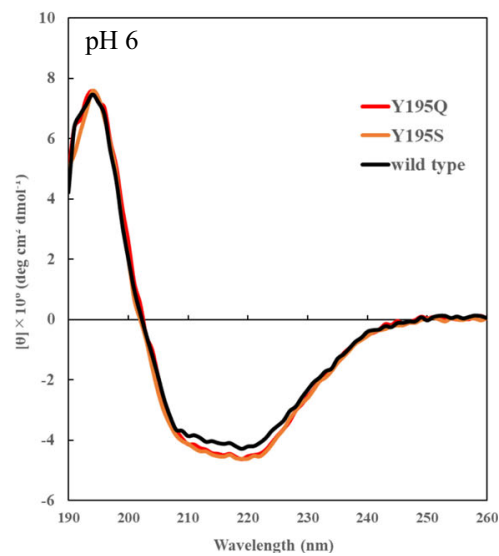

optimum $\mathrm{pH}$ from 11 to 10 , and twofold higher activity at $\mathrm{pH}$ 8.5 (Jakob et al. 2013).

Zhao and Feng (2018) used error-prone PCR random mutagenesis on the alkaline serine protease from Bacillus

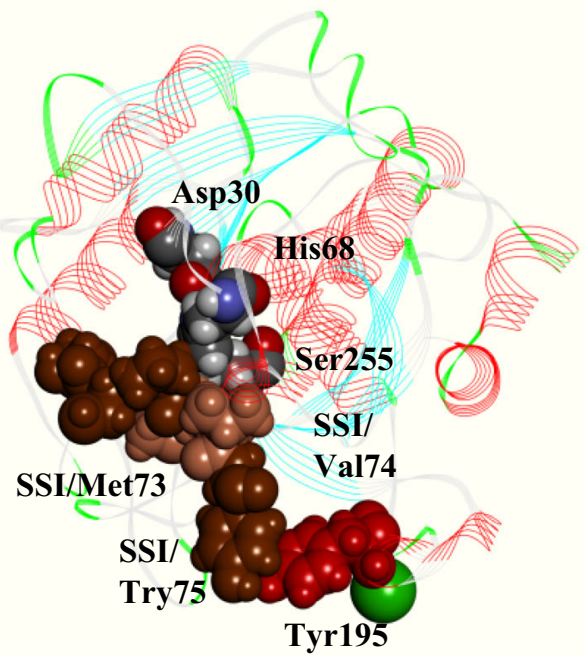

Fig. 6 Stereo view of the structure of the N-domain of KP-43 in complex with SSI. The N-domain of KP-43 is shown as a line ribbon representation. Met70-Tyr75 of SSI is shown as a CPK representation in deep brown, Met73 of SSI (P1 residue) and Val74 of SSI (P1' residue) are shown in light brown. Asp30, His68, and Ser255 of KP-43 are shown as pumilus and generated 7 mutants exhibiting increased caseinolytic activity. Four of the 7 substitution sites were located on the protein surface; notably, Thr162Ile, located in a flexible loop, exhibited 2.4-fold increased caseinolytic activity

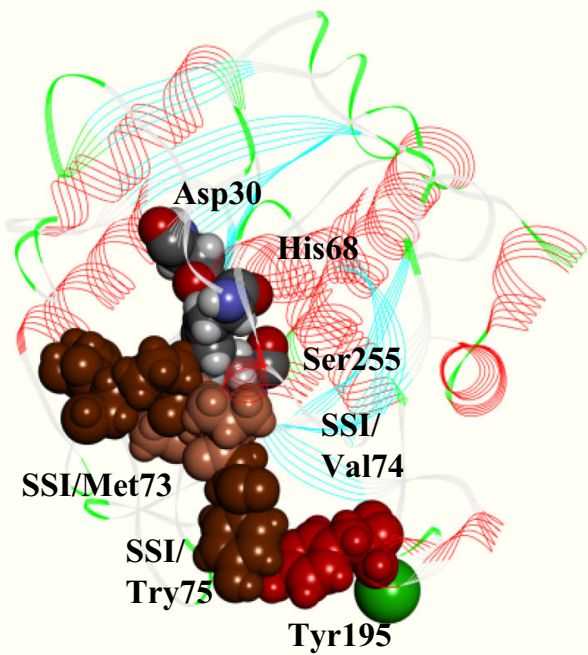

CPK representations (white for hydrogen atoms, gray for carbon atoms, blue for nitrogen atoms, and red for oxygen atoms). Tyr195 is shown as a CPK representation in red. Calcium ion is shown as a green ball. The structures were created using DS Visualizer (Biovia) 
(Zhao and Feng 2018). Previous studies demonstrated that both charged and uncharged amino acid residues on the protein surface can increase proteolytic activity. However, the detailed mechanism underlying the increased proteolytic activity and effect of substitutions with other amino acid residues at the mutation sites remain unclear.

Mutation sites and the effect of mutations are often discussed in reference to amino acid sequence alignments or homology models with other subtilisin homologs (e.g., subtilisin BPN'). In KP-43, Tyr195 is located in an insertion not found in other subtilisin homologs (Okuda et al. 2013). Accordingly, we could not directly compare our results with previous studies examining subtilisin mutations around position 195.

The crystal structure of KP-43 suggests that the side chain of Tyr195 is oriented out toward the solvent. Thus, the hydrophobicity of the side chain directly affects the manner of interaction with water and substrate molecules. As shown in Fig. 2, both the caseinolytic activity and $\mathrm{pH}$ profile changed dramatically upon substitution at position 195. It is very interesting that a single mutation in KP-43 produced three different $\mathrm{pH}$ activity profiles. Charged and hydrophilic amino acid residues (Gln, Thr, Glu, Arg, Lys, Gly, Asp, or Asn) rendered KP-43 a high-activity-type enzyme, whereas hydrophilic and hydrophobic amino acid residues (Ser, Ala, Val, Leu, Cys, Met, Pro, His, or Ile) rendered KP-43 a mid-activity-type enzyme. In contrast, hydrophobic aromatic amino acid residues (Phe, Tyr, or Trp) rendered KP-43 a low-activity-type enzyme.

Tyr195 is surrounded by four hydrophobic aromatic amino acid residues (Phe192, Phe205, Phe226, and Trp241) (Fig. 1b). Thus, we hypothesized that Tyr, Phe, and Trp residues at position 195 exhibit aromatic $\pi-\pi$ interactions with these surrounding aromatic amino acid residues. The resulting restrained flexibility of the $\mathrm{Ca}^{2+}$-binding loop reduces the caseinolytic activity compared with other amino acid residue substitutions.

As shown in Fig. 3a-c, at $\mathrm{pH} 8-10$, hydrophobicity of the amino acid residue at position 195 was negatively correlated with caseinolytic activity. However, this correlation gradually weakened with declining $\mathrm{pH}$. At pH 6, the correlation between the hydrophobicity of the amino acid residue at position 195 and caseinolytic activity reversed to positive (Fig. 3e). Figure 4 shows the relationship between the hydrophobicity of the amino acid residue at position 195 and $k$ cat $/ K m$ toward AAPL at $\mathrm{pH} 10$ and $\mathrm{pH}$ 6. Unlike casein, no relationship was found, and the hydrolysis efficiency ranking of the 20 variants was essentially the same at $\mathrm{pH} 10$ and pH 6. Furthermore, Fig. 5 suggests that there is no conformational change in KP-43 caused by the substitution at position 195 . These results indicate that the observed variation in caseinolytic activity following substitution at position 195 was not due to a change in the active cleft, secondary structure, or tertiary structure of KP-43 but rather to the efficiency of the interaction with casein.

Casein, a small protein (molecular weight $<20 \mathrm{kDa}$ ) in milk, is an unstructured protein that forms micelles. The structure of the casein micelle has been studied for over 50 years, and various models have been proposed (Farrell Jr et al. 2006; Horne 2006). Because casein has a hydrophilic and hydrophobic domain, it exhibits amphiphilic properties. The hydrophobic core of casein micelles is surrounded by hydrophilic casein protein molecules. Liu and Guo (2008) investigated the effect of $\mathrm{pH}$ on the structure of casein micelles and demonstrated that the micelle structure is more compact at low $\mathrm{pH}$ and looser at high $\mathrm{pH}$ (in the range of $\mathrm{pH}$ 6-12) due to changes in electrostatic repulsion (casein theoretical pI is 4.8).

Figure 6 shows a docking model of the KP-43 and SSI complex, which indicates that Tyr195 interacts with Tyr75 of the SSI (P2' residue). Consequently, the amino acid residue at position 195 likely affects the efficiency of hydrolysis due to differences in the efficiency of interaction with macromolecular substrates. Accordingly, we assume that the reversal of the correlation between the hydrophobicity of the amino acid residue at position 195 and caseinolytic activity is due to changes in the hydrophobicity of casein micelles at different $\mathrm{pH}$ values. However, in the case of hydrolysis of AAPL, Leu is the $\mathrm{P} 1$ residue, and $p$-nitroanilide is located in the position of the P1' residue that likely does not interact with Tyr195. Therefore, substitution of Tyr195 appears to have little effect on the catalytic efficiency toward AAPL compared with the hydrolysis of proteinaceous substrates.

A number of studies have demonstrated that substitution of residues remote from the active center or substrate binding site can improve the catalytic efficiency of enzymes other than proteases. For example, Wilding et al. (2019) used a molecular dynamics approach to predict critical amino acid residues on the protein surface that interact with substrates and affect the catalytic efficiency of KES23360 transaminase. The authors demonstrated that mutation of the predicted residues (Glu178Asp, Gly179Arg, and Gln142Asn) increased the catalytic efficiency and proposed that these amino acid residues are involved in directing substrates into the active center (Wilding et al. 2018). Additionally, increasing the hydrophobicity of a specific region of the protein surface of polyesterhydrolyzing enzyme (polyesterase) increases the efficiency of polyethyleneterephthalate (PET; a hydrophobic waterinsoluble substrate) hydrolysis (Biundo et al. 2018). Acero et al. (2013) conducted site-directed mutagenesis of amino acid residues on the surface of a cutinase from Thermobifida cellulosilytica DSM44535. Although the Arg29Asn/ Ala30Val double mutant exhibited fourfold higher hydrolysis activity than the wild-type enzyme, the Gln65Glu mutant exhibited no hydrolysis of PET, regardless of the ability to hydrolyze soluble substrates (Acero et al. 2013). These results demonstrate that some residues on the protein surface are critically important for access to substrates but do not affect the structure of the active center.

The introduction of mutations on the surface of a protein is thought to be advantageous because the original substrate 
specificity can be retained. However, the results of this study showed that even a single mutation on the protein surface can dramatically increase proteolytic activity and differentially affect the $\mathrm{pH}$ profile without inducing a conformational change.

We demonstrated the importance of the relationship between the hydrophobicity of the critical amino acid residue on the surface of KP-43 and the surface properties of macromolecular substrates. We intend to investigate the relationship between the protein surface and various macromolecular substrates in more detail in order to improve enzyme activity in accordance with the features of macromolecular substrates.

Author contribution statement MO designed the research and conducted the experiments and analyses. TO prepared the molecular simulation and interpreted the results. AK conducted spectroscopic analyses. MO wrote the first draft of the manuscript. AK and YT critically reviewed the manuscript. All authors approved the final manuscript.

\section{Compliance with ethical standards}

Conflict of interest The authors declare that they have no competing interests.

Ethical approval This article does not contain any studies with human participants or animals performed by any of the authors.

Open Access This article is licensed under a Creative Commons Attribution 4.0 International License, which permits use, sharing, adaptation, distribution and reproduction in any medium or format, as long as you give appropriate credit to the original author(s) and the source, provide a link to the Creative Commons licence, and indicate if changes were made. The images or other third party material in this article are included in the article's Creative Commons licence, unless indicated otherwise in a credit line to the material. If material is not included in the article's Creative Commons licence and your intended use is not permitted by statutory regulation or exceeds the permitted use, you will need to obtain permission directly from the copyright holder. To view a copy of this licence, visit http://creativecommons.org/licenses/by/4.0/.

\section{References}

Acero EH, Ribitsch D, Dellacher A, Zitzenbacher S, Marold A, Steinkellner G, Gruber K, Schwab H, Guebitz GM (2013) Surface engineering of a cutinase from Thermobifida cellulosilytica for improved polyester hydrolysis. Biotechnol Bioeng 110(10):25812590. https://doi.org/10.1002/bit.24930

Biundo A, Ribitsch D, Guebitz GM (2018) Surface engineering of polyester-degrading enzymes to improve efficiency and tune specificity. Appl Microbiol Biotechnol 102(8):3551-3559. https://doi. org/10.1007/s00253-018-8850-7

Black SD, Mould DR (1991) Development of hydrophobicity parameters to analyze proteins which bear post- or cotranslational modifications. Anal Biochem 193(1):72-82. https://doi.org/10.1016/00032697(91)90045-U

Bode W, Papamokos E, Musil D, SeemuellerU FH (1986) Refined $1.2 \AA$ crystal structure of the complex formed between subtilisin Carlsberg and the inhibitor eglin c. Molecular structure of eglin and its detailed interaction with subtilisin. EMBO J 5(4):813-818. https://doi.org/ $10.1002 / \mathrm{j} .1460-2075.1986 . t b 04286 . x$
Bryan PN (2000) Protein engineering of subtilisin. Biochim Biophys Acta 1543(2):203-222. https://doi.org/10.1016/S0167-4838(00) 00235-1

de Kreij A, van den Burg B, Venema G, Vriend G, Eijsink VG, Nielsen JE (2002) The effects of modifying the surface charge on the catalytic activity of a thermolysin-like protease. J Biol Chem 277(18): 15432-15438. https://doi.org/10.1074/jbc.M200807200

Estell DA, Graycar TP, Miller JV, Powers DB, Burnier JP, Ng PG, Wells JA (1986) Probing steric and hydrophobic effects on enzymesubstrate interactions by protein engineering. Science 233(4764): 659-663. https://doi.org/10.1126/science.233.4764.659

Farrell HM Jr, Malin EL, Brown EM, Qi PX (2006) Casein micelle structure: what can be learned from milk synthesis and structural biology? Curr Opin Colloid Interface Sci 11(2-3):135-147. https:// doi.org/10.1016/j.cocis.2005.11.005

Feller BE, Kellis JT Jr, Cascão-Pereira LG, Robertson CR, Frank CW (2010) The role of electrostatic interactions in protease surface diffusion and the consequence for interfacial biocatalysis. Langmuir 26(24):18916-18925. https://doi.org/10.1021/la103080a

Gupta R, Beg QK, Lorenz P (2002) Bacterial alkaline proteases: molecular approaches and industrial applications. Appl Microbiol Biotechnol. 59(1):15-32. https://doi.org/10.1007/s00253-0020975-y

Hirono S, Akagawa H, Mitsui Y, Iitaka Y (1984) Crystal structure at 2.6 $\AA$ resolution of the complex of subtilisin BPN' with Streptomyces subtilisin inhibitor. J Mol Biol 178(2):389-413. https://doi.org/10. 1016/0022-2836(84)90150-5

Ho SN, Hunt HD, Horton RM, Pullen JK, Pease LR (1989) Site-directed mutagenesis by overlap extension using the polymerase chain reaction. Gene 77(1):51-59. https://doi.org/10.1016/0378-1119(89) 90358-2

Horne DS (2006) Casein micelle structure: models and muddles. Curr Opin Colloid Interface Sci 11(2-3):148-153. https://doi.org/10. 1016/j.cocis.2005.11.004

Jakob F, Martinez R, Mandawe J, Hellmuth H, Siegert P, Maurer KH, Schwaneberg U (2013) Surface charge engineering of a Bacillus gibsonii subtilisin protease. Appl Microbiol Biotechnol 97(15): 6793-6802. https://doi.org/10.1007/s00253-012-4560-8

Kalisz HM (1988) Microbial proteinases. Adv Biochem Eng Biothechnol 36:1-65. https://doi.org/10.1007/BFb0047944

Kobayashi T, Hakamada Y, Adachi S, Hitomi J, Yoshimatsu T, Koike K, Kawai S, Ito S (1995) Purification and properties of an alkaline protease from alkalophilic Bacillus sp. KSM-K16. Appl Microbiol Biotechnol 43(3):473-481. https://doi.org/10.1007/BF00218452

Laemmli UK (1970) Cleavage of structural proteins during the assembly of the head of bacteriophage T4. Nature 227(5259):680-685. https:// doi.org/10.1038/227680a0

Liu Y, Guo R (2008) pH-dependent structures and properties of casein micelles. Biophys Chem 136(2-3):67-73. https://doi.org/10.1016/j. bpc.2008.03.012

Mcphalen CA, Svendsen I, Jonassen I, James MNG (1985) Crystal and molecular structure of chymotrypsin inhibitor 2 from barley seeds in complex with subtilisin Novo. Proc Natl Acad Sci USA 82(21): 7242-7246. https://doi.org/10.1073/pnas.82.21.7242

Nonaka T, Fujihashi M, Kita A, Saeki K, Ito S, Horikoshi K, Miki K (2004) The crystal structure of an oxidatively stable subtilisin-like alkaline serine protease, $\mathrm{KP}-43$, with a C-terminal $\beta$-barrel domain. J Biol Chem 279(45):47344-47351. https://doi.org/10.1074/jbc. M409089200

Okuda M, Ozawa T, Tohata M, Sato T, Saeki K, Ozaki K (2013) A single mutation within a $\mathrm{Ca}^{2+}$ binding loop increases proteolytic activity, thermal stability, and surfactant stability. Biochim Biophys Acta (BBA) - Proteins Proteomics 1834(3):634-641. https://doi.org/10. 1016/j.bbapap.2012.12.019

Saeki K, Okuda M, Hatada Y, Kobayashi T, Ito S, Takami H, Horikoshi K (2000) Novel oxidatively stable subtilisin-like serine proteases 
from alkaliphilic Bacillus spp.: enzymatic properties, sequences, and evolutionary relationships. Biochem Biophys Res Commun 279(2): 313-319. https://doi.org/10.1006/bbrc.2000

Saeki K, Hitomi J, Okuda M, Hatada Y, Kageyama Y, Takaiwa M, Kubota H, Ito S (2002) A novel species of alkaliphilic Bacillus that produces an oxidatively stable alkaline serine protease. Extremophiles 6(1):65-72. https://doi.org/10.1007/s007920100224

Siezen RJ, Leunissen JAM (1997) Subtilases: the superfamily of subtilisin-like serine proteases. Protein Sci 6:501-523. https://doi. org/10.1002/pro.5560060301

Taguchi S, Komada S, Momose H (2000) The complete amino acid substitutions at position 131 that are positively involved in cold adaptation of subtilisin BPN'. Appl Environ Microbiol. 66(4): 1410-1415. https://doi.org/10.1128/AEM.66.4.1410-1415.2000

Thomas PG, Russell AJ, Fersht AR (1985) Tailoring the $\mathrm{pH}$ dependence of enzyme catalysis using protein engineering. Nature 318:375-376. https://doi.org/10.1038/318375a0

Wells JA, Estell DA (1988) Subtilisin - an enzyme designed to be engineered. Trends Biochem Sci 13(8):291-297. https://doi.org/ 10.1016/0968-0004(88)90121-1

Wells JA, Cunningham BC, Graycar TP, Estell DA (1987a) Recruitment of substrate-specificity properties from one enzyme into a related one by protein engineering. Proc Natl Acad Sci USA 84(15): 5167-5171. https://doi.org/10.1073/pnas.84.15.5167

Wells JA, Powers DB, Bott RR, Graycar TP, Estell DA (1987b) Designing substrate specificity by protein engineering of electrostatic interactions. Proc Natl Acad Sci USA 84(5):1219-1223. https:// doi.org/10.1073/pnas.84.5.1219

Wilding M, Scott C, Warden AC (2018) Computer-guided surface engineering for enzyme improvement. Sci Rep 8:11998. https://doi.org/ 10.1038/s41598-018-30434-5

Wilding M, Hong N, Spence M, Buckle AM, Jackson CJ (2019) Protein engineering: the potential of remote mutations. Biochem Soc Trans 47(2):701-711. https://doi.org/10.1042/BST20180614

Zhao HY, Feng H (2018) Engineering Bacillus pumilus alkaline serine protease to increase its low-temperature proteolytic activity by directed evolution. BCM Biotechnol 18:34. https://doi.org/10.1186/ s12896-018-0451-0

Publisher's note Springer Nature remains neutral with regard to jurisdictional claims in published maps and institutional affiliations. 